As-Syifaa Jurnal Farmasi Juli 2020;12(1):16-21.

ISSN : 2502-9444 (electronic); 2085-4714 (printed)

Journal Homepage : http://jurnal.farmasi.umi.ac.id/index.php/as-syifaa

\title{
UJI STABILITAS DAN KEAMANAN GRANUL EKSTRAK BATANG SELEDRI (Avium graveolens) SEBAGAI BIOLARVASIDA Aedes aegypti
}

\author{
Dian Kartikasari, Dani Suryaningrat
}

\author{
Program Studi Farmasi Akademi Farmasi Yarsi Pontianak \\ Email: diankartikasari223@gmail.com
}

\begin{abstract}
Long-term use of synthetic insecticides or larvicides can cause undesirable things, so plantbased biolarvacides need to be developed that do not cause harm and are more environmentally friendly. The aim of this study was to determine the total phenolic value of Avium graveolens extract granules as well as to determine the temperature stability of good storage for larvicidal granules of Avium graveolens extract and to know the safe limits of the use of larvicide granules of Avium graveolens extract based on $L C_{50}$ values. Total phenol test of Avium graveolens extract was carried out using Folin Cetaceau reagent, then the stability test of Avium graveolens extract granules was carried out by storing Avium graveolens extract granules at several different temperatures for the next 28 days based on physical properties and total phenol values on Avium graveolens extract granules before being saved and after being stored. Then the safety test was carried out by the BSLT method (Brine Shrimp Lethality Test) by looking at the number of deaths of Artemia saline larvae and then $L C_{50}$ values were calculated. The results showed that the total phenol content of Avium graveolens extract was $0.23605 \% \mathrm{~b} / \mathrm{b}$. And the results of the stability test showed that the granules did not change physically even though they were stored at $60^{\circ} \mathrm{C}$ for 28 days. The results of the toxicity test obtained $L C_{50}$ values of $608,98 \mathrm{mcg} / \mathrm{g}$, meaning that Avium graveolens extract granules are safe to use.
\end{abstract}

Key Words: Total phenolic, stability test, safety test.

\section{PENDAHULUAN}

Berdasarkan penelitian ${ }^{1}$, menunjukkan bagian batang seledri memiliki potensi paling tinggi sebagai larvasida dibandingkan bagian lain tanaman seledri. Formula larvasida nabati berbahan aktif ekstrak batang seledri telah dilakukan², dengan hasil penelitian menunjukkan granul larvasida yang dihasilkan memenuhi persyaratan yang ditentukan dan didapatkan konsentrasi efektif dalam membunuh 50\% larva nyamuk Aedes aegypti. Namun demikian, formula yang telah ditemukan ini belum diketahui suhu yang baik untuk penyimpanan agar granul tetap tidak berubah secara fisik atau stabilitas selama penyimpanan sehingga perlu dilakukan uji stabilitas serta dilakukan pengujian keamanan. Pentingnya dilakukan pengujian keamanan dikarenakan budaya masyarakat di Kalimantan
Barat cenderung menyimpan persediaan air pada tempat-tempat penampungan air di sekitar rumahnya, dan menggunakan air tersebut untuk konsumsi rumah tangga. ${ }^{3}$

Stabilitas obat merupakan salah satu aspek penting dalam mendapatkan suatu sediaan obat yang baik. Beberapa faktor yang mempengaruhi kestabilan suatu obat salah satunya yaitu faktor suhu penyimpanan. Berdasarkan beberapa hasil penelitian menunjukkan adanya pengaruh suhu terhadap stabilitas obat baik dilihat dari sifat fisika dan kimia serta bioavailabilitas obat. pada penelitian ${ }^{4}$. Diketahui bahwa hasil uji stabilitas formula larvasida nabati minyak biji kamandarah yang disimpan pada temperatur 30; 40 dan $50^{\circ} \mathrm{C}$ selama 28 hari menujukkan tidak ada perubahan fisik pada granul. Selama penyimpanan terjadi peningkatan kandungan 
piperin dalam formula larvasida antara 0,62,34\%. Uji durabilitas formula larvasida terhadap larva Aedes aegypti menujukkan penurunan potensi larvasida sampai di bawah $50 \%$ pada hari ke 12 setelah aplikasi.

Untuk mendapatkan suatu sediaan yang baik, selain diharapkan dapat stabil selama penyimpanan, diharapakan juga sediaan obat tersebut aman digunakan oleh manusia, sehingga diperlukan adanya pengujian keamanan suatu sediaan obat, yaitu dengan cara dilakukan uji toksisitas akut dengan menentukan nilai $\mathrm{LC}_{50}$ dari bahan yang akan digunakan. $\mathrm{LC}_{50}$ harus ditentukan karena nilai ini digunakan dalam penilaian rasio manfaat (khasiat) dan daya racun yang dinyatakan sebagai indeks terapi obat. Makin besar indeks terapi, makin aman obat tersebut jika digunakan 5 . Berdasarkan uraian diatas maka peneliti akan melakukan penelitian dengan judul "Uji Stabilitas dan Keamanan Granul Ekstrak Batang Seledri (Avium Graveolens) sebagai Biolarvasida Aedes aegypti. Agar didapatkan formula granul yang stabil pada penyimpanan yang efektif dan aman, sehingga hasil dari penelitian ini dapat meningkatkan kontribusi tanaman obat Indonesia

\section{METODE PENELITIAN}

\section{Alat dan bahan}

\section{Uji total fenol ekstrak batang seledri}
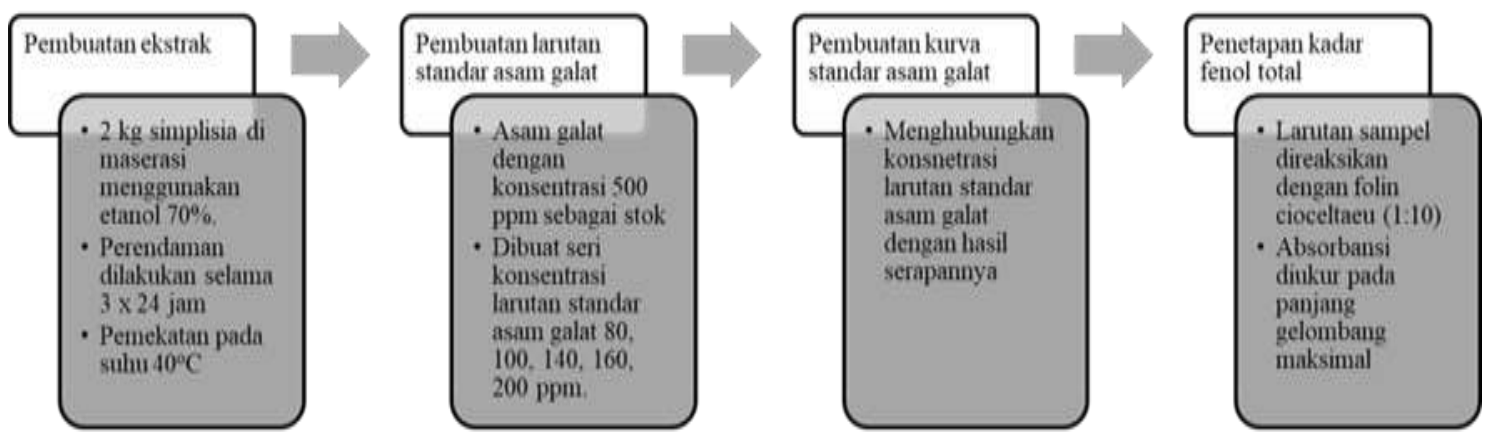

Gambar 1. Proses Kerja Uji Total Fenol ${ }^{6}$ alat-alat gelas, blender, counter untuk menghitung larva, Rotary evaporator, Stop watch, termometer, oven, cawan petri, ayakan mesh 12 dan 16, wadah transparan, pipet volume, spektrofotometer UV-Vis, frezz drying, oven pengering. Sedangkan bahan yang dipakai yaitu batang seledri, aquadest, etanol 70\%, larva Artemia salina, kertas saring, PVP, laktosa, asam galat, reagen Folin-ciocalteau,

\section{Prosedur kerja}

\section{Pembuatan ekstrak kering batang seledri ${ }^{2}$}

Ekstrak batang seledri dibuat dengan cara simplisia batang seledri yang sudah dibersihkan, kemudian dikeringkan dengan oven pada suhu $40^{\circ} \mathrm{C}$, hingga didapatkan kadar air kurang dari 10\%. Simplisia yang sudah kering selanjutnya dihaluskan, kemudian di maserasi pada wadah kaca sebanyak $2 \mathrm{~kg}$ menggunakan pelarut etanol $70 \%$ sampai semua simplisia terendam pada suhu kamar. Perendaman dilakukan selama $3 \times 24$ jam. Selama perendaman, sesekali di aduk. Pada setiap 24 jam, filtrat di ganti dengan pelarut yang baru. Filtrat hasil penyarian kemudian di pekatkan menggunakan rotary evaporator suhu $40^{\circ} \mathrm{C}$ hingga didapat ekstrak kental. Kemudian dilanjutkan dengan metode frezze drying untuk mendapatkan ekstrak kering. $\mathrm{Na} 2 \mathrm{CO} 3$. 


\section{Uji Stabilitas Granul ekstrak batang seledri}

Pembuatan granul biolarvasida ekstrak batang seledri formula granul dengan karakteristik terbaik dari penelitian Kartikasari \&
Suhaimi, $2018^{2}$ yang akan digunakan pada pengujian keamanan biolarvasida terhadap larva Artemia saline.

Tabel 1. Formula granul ekstrak batang seledri

\begin{tabular}{lccccc}
\hline \multicolumn{1}{c}{ Bahan } & Formula 1 & Formula 2 & Formula 3 & Formula 4 & Formula 5 \\
\hline Ekstrak batang seledri & $1000 \mathrm{mcg} / \mathrm{g}$ & $500 \mathrm{mcg} / \mathrm{g}$ & $100 \mathrm{mcg} / \mathrm{g}$ & $50 \mathrm{mcg} / \mathrm{g}$ & $25 \mathrm{mcg} / \mathrm{g}$ \\
Pvp & $2 \%$ & $2 \%$ & $2 \%$ & $2 \%$ & $2 \%$ \\
Laktosa & $\mathrm{Ad} 100 \mathrm{~g}$ & $\mathrm{Ad} 100 \mathrm{~g}$ & $\mathrm{Ad} 100 \mathrm{~g}$ & $\mathrm{Ad} 100 \mathrm{~g}$ & $\mathrm{Ad} 100 \mathrm{~g}$ \\
\hline
\end{tabular}

\section{Pengujian keamanan granul biolarvasida ekstrak daun seledri}

Uji keamanan pada granul biolarvasida ekstrak daun seledri dapat dilakukan dengan uji toksisitas akut dengan metode Brine Shimp Lethality Test (BSLT) menggunakan larva
Artemia saline. Metode BSLT digunakan untuk mengetahui toksisitas sampel secara umum. Adapun prosesnya sebagai berikut:

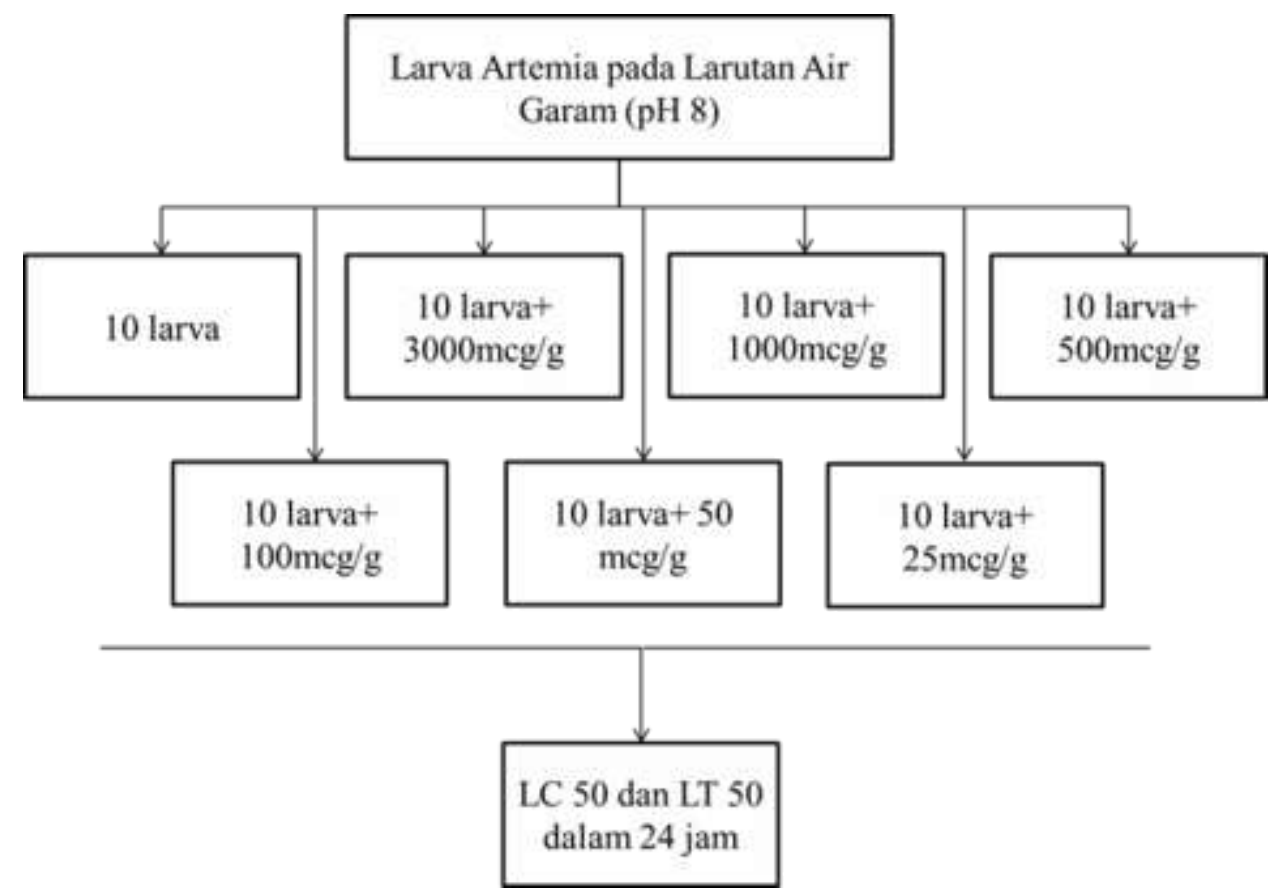

Gambar 2. Alur uji toksisitas ${ }^{8}$

\section{Analisa Data}

Analisa data dilakukan untuk mengetahui tujuan penelitian. untuk mengetahui nilai total fenol pada ekstrak batang seledri menggunakan alat Spektrofotometri dengan reagen Folin cioceltaeu kemudian dihitung dengan rumus persen kadar. Untuk mengetahui stabilitas granul ekstrak batang seledri (Apium graveolens) selama penyimpanan, dilakukan analisis secara deskriptif. Untuk mengetahui dosis mematikan $50 \%$ ( $\mathrm{LC}_{50}$ ) larva artemia dalam waktu 24 jam granul ekstrak. 


\section{HASIL DAN PEMBAHASAN}

\section{Hasil Uji Total Fenol Ekstrak Batang Seledri}

Tabel 2. Hasil Uji Penetapan Total Fenol Ekstrak Batang Seledri

\begin{tabular}{ccc}
\hline Sampel & Replikasi & Kadar \%b/b \\
\hline \multirow{2}{*}{ Ekstrak batang seledri } & 1 & 0,23693 \\
& 2 & 0,24005 \\
& 3 & 0,23177 \\
\hline
\end{tabular}

Berdasarkan tabel diatas, diketahui kadar ekstrak batang seledri setelah di rata-rata didapatkan nilai sebesar 0,23625\%b/b, artinya dalam 100 gram ekstrak batang seledri terdapat 0,23625 gram senyawa fenol, yang dinyatakan dalam GAE (Gallic Acid Eqivalent).
Hal ini sesuai dengan hasil penelitian ${ }^{6}$. Yaitu pada herba seledri kandungan total fenol sebesar $0,327 \% \mathrm{~b} / \mathrm{b}$. tingginya kandungan fenol pada ekstrak seledri menunjukkan aktivitas granul larvasida salah satunya berasal dari senyawa fenol.

\section{Hasil uji stabilitas Granul Ekstrak Batang Seledri}

Tabel 3. Hasil Uji Stabilitas Granul Ekstrak Batang Seledri

\begin{tabular}{cccccccc}
\hline \multirow{2}{*}{ Formula } & Hari ke- & \multicolumn{3}{c}{$\mathbf{1}$} & \multicolumn{4}{c}{ 28 } \\
\cline { 3 - 8 } & Suhu $40^{\circ} \mathrm{C}$ & Bau & Warna & Bentuk & Bau & Warna & Bentuk \\
\hline \multirow{2}{*}{1} & Suhu $50^{\circ} \mathrm{C}$ & $\mathrm{K}$ & $\mathrm{PK}$ & $\mathrm{G}$ & $\mathrm{K}$ & $\mathrm{PK}$ & $\mathrm{G}$ \\
& Suhu $60^{\circ} \mathrm{C}$ & $\mathrm{K}$ & $\mathrm{PK}$ & $\mathrm{G}$ & $\mathrm{K}$ & $\mathrm{PK}$ & $\mathrm{G}$ \\
& Suhu $40^{\circ} \mathrm{C}$ & $\mathrm{K}$ & $\mathrm{PK}$ & $\mathrm{G}$ & $\mathrm{K}$ & $\mathrm{PK}$ & $\mathrm{G}$ \\
& Suhu $50^{\circ} \mathrm{C}$ & $\mathrm{K}$ & $\mathrm{PK}$ & $\mathrm{G}$ & $\mathrm{K}$ & $\mathrm{PK}$ & $\mathrm{G}$ \\
2 & Suhu $60^{\circ} \mathrm{C}$ & $\mathrm{K}$ & $\mathrm{PK}$ & $\mathrm{G}$ & $\mathrm{K}$ & $\mathrm{PK}$ & $\mathrm{G}$ \\
\hline \multirow{2}{*}{3} & Suhu $40^{\circ} \mathrm{C}$ & $\mathrm{K}$ & $\mathrm{PK}$ & $\mathrm{G}$ & $\mathrm{K}$ & $\mathrm{PK}$ & $\mathrm{G}$ \\
& Suhu $50^{\circ} \mathrm{C}$ & $\mathrm{K}$ & $\mathrm{PK}$ & $\mathrm{G}$ & $\mathrm{K}$ & $\mathrm{PK}$ & $\mathrm{G}$ \\
& Suhu $60^{\circ} \mathrm{C}$ & $\mathrm{K}$ & $\mathrm{PK}$ & $\mathrm{G}$ & $\mathrm{K}$ & $\mathrm{PK}$ & $\mathrm{G}$ \\
\hline & & & &
\end{tabular}

Keterangan: (K) khas; (PK) putih kekuningan; (G) granul.

Berdasarkan tabel diatas, didapatkan bahwa pada penyimpanan suhu $40^{\circ} \mathrm{C}$ hari pertama granul berbau khas, berwarna putih kekuningan dan berbentuk granul. Setelah disimpan selama 28 hari granul berbau khas, berwarna putih kekuningan dan berbentuk granul. Hal yang sama juga terlihat pada penyimpanan pada suhu $50^{\circ} \mathrm{C}$ dan $60^{\circ} \mathrm{C}$. Hal ini menunjukkan bahwa granul tidak mengalami perubahan secara fisik meliputi bau, warna dan bentuk selama penyimpanan selama 28 hari. Pada penelitian ${ }^{4}$ yang telah dilakukan mengenai uji stabilitas dengan cara penyimpanan pada beberapa tingkatan temperatur selama 28 hari menujukkan bahwa tidak ada perubahan fisik pada granul. Hal ini menunjukkan bahwa granul ekstrak batang seledri dapat disimpan dalam waktu yang lama.

Hasil UJi Toksisitas Akut Granul Ekstrak Batang Seledri

Uji toksisitas akut adalah suatu pengujian untuk mendeteksi efek toksik yang muncul dalam waktu singkat setelah pemberian sediaan uji yang diberikan dalam dosis tunggal, atau dosis berulang yang diberikan dalam waktu 24 jam. Prinsip uji toksisitas akut oral yaitu, sediaan uji dalam beberapa tingkat dosis diberikan pada beberapa kelompok hewan uji dengan satu dosis per kelompok, kemudian dilakukan pengamatan terhadap 
adanya efek toksik dan kematian7. Pada penelitian ini, uji toksisitas akut dilakukan dengan tujuan untuk melihat keamanan penggunaan granul ekstrak batang seledri terhadap larva Artemia salina dengan metode Brine Shrimp Lethal Test (BSLT). Hasil persen kematian larva Artemia salina dapat dilihat pada tabel 4.

Tabel 4. Nilai Konsentrasi VS Persen Kematian Artemia salina

\begin{tabular}{cccc}
\hline Konsentrasi mcg/g & Log Konsentrasi & Probit & Persen Kematian \\
\hline 1000 & 3 & 4,59 & 34 \\
500 & 2.699 & 4,53 & 32 \\
100 & 2 & 4,23 & 22 \\
50 & 1.699 & 4,08 & 18 \\
25 & 1.398 & 3,72 & 10 \\
0 & 0 & 0 & 0 \\
\hline
\end{tabular}

Berdasarkan tabel 4 diatas diketahui semakin tinggi konsentrasi perlakuan maka semakin tinggi juga jumlah atau persen kematian larva Artemia salina, selanjutnya dari data konsentrasi di konversi menjadi log konsentrasi dan di cocokkan dengan tabel porbit. Hasil log konsentrasi di hubungkan dengan nilai probit untuk mendapatkan garis linier, sehingga didapatlah rumus regresi linier seperti pada gambar 3 dibawah ini.

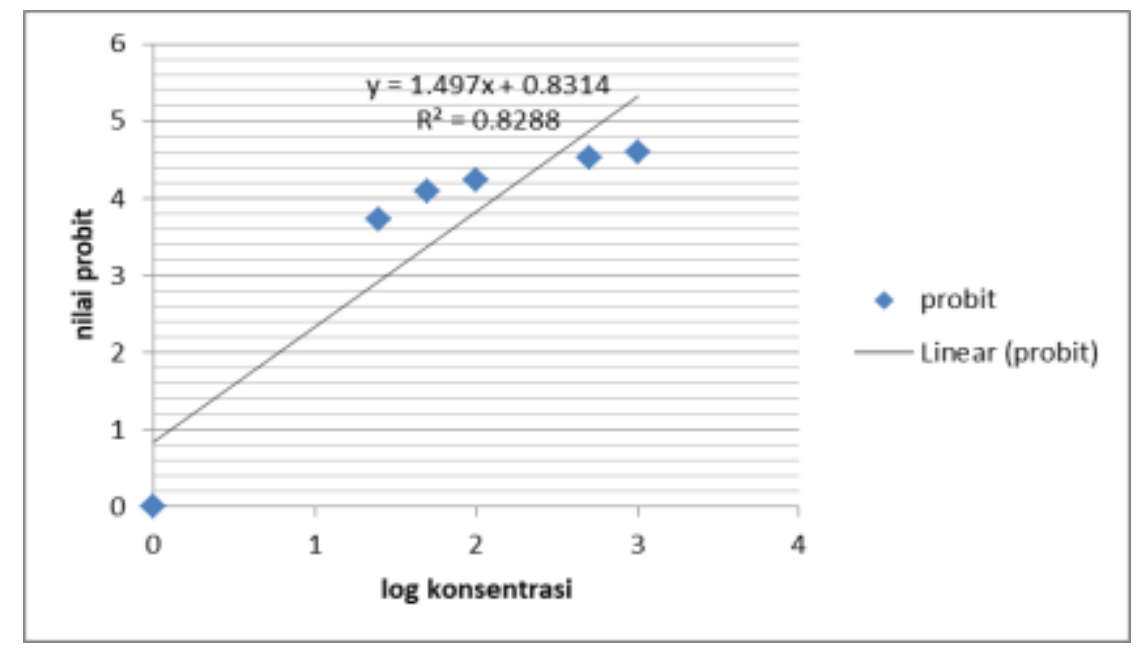

Gambar 3. Kurva Log Konsentrasi VS nilai Probit larva Artemia salina

Berdasarkan tabel dan grafik diatas kemudian dihitung nilai LC50 dan didapatkan nilai LC50 sebesar $608,98 \mathrm{mcg} / \mathrm{g}$. Hal ini menunjukkan bahwa granul ekstrak batang masuk kategori toksik ringan (500 - 5000 $\mathrm{mcg} / \mathrm{g}),{ }^{7}$ sehingga aman digunakan.

\section{KESIMPULAN}

Kandungan total fenol pada ekstrak batang seledri sebesar $0,23625 \% \mathrm{~b} / \mathrm{b}$, granul batang seledri tidak mengalami perubahan secara fisik setelah disimpan selama 28 hari pada suhu $40^{\circ} \mathrm{C}, 50^{\circ} \mathrm{C}$ dan $60^{\circ} \mathrm{C}$. Hasil uji toksisitas didapatkan nilai LC50 sebesar $608,98 \mathrm{mcg} / \mathrm{g}$. hal ini menunjukkan granul ekstrak batang seledri aman karena LC50 500 - $5000 \mathrm{mcg} / \mathrm{g}$. 


\section{UCAPAN TERIMA KASIH}

Ucapan terima kasih penulis sampaikan kepada Direktorat Jenderal Riset dan Pengembangan, Kementrian Riset dan Pendidikan Tinggi atas dana hibah penelitian yang telah diberikan melalui skema Penelitian Dosen Pemula tahun 2019.

\section{DAFTAR PUSTAKA}

1. Stefanus VRC. Ekstrak Etanol Batang Seledri (Apium graveolens) Sebagai Larvasida Terhadap Larva Aedes aegypti (Skripsi). Salatiga : Universitas Kristen Duta Wacana, 2013.

2. Kartikasari D dan Suhaimi. Uji Efektivitas Granul Ekstrak Batang Seledri (Avium graveolens) Pada Telur, Larva dan Pupa Aedes aegypti. Laporan Penelitian Hibah PDP. Pontianak: Akademi Farmasi Yarsi Pontianak, 2018.

3. Dinkes Kalbar. Profil Kesehatan Provinsi kalimantan Barat Tahun 2011. Pontianak: Dinas Kesehatan Provinsi Kalimantan Barat, 2011.

4. Winoto E, Iswantini D, Batubara I, Hadi UK. Formulasi Larvasida Nabati Berbasis
Minyak Biji Kamandrah (Cronton tiglium L.) Terstandar Sebagai Pencegah Penyakit Demam Berdarah Dengue. Bul. Littro. 2013;24(2):101-110.

5. Soemardji AA, Kumolosari E, Aisyah C. Toksisitas Akut dan Penentuan DL50 Oral Ekstrak Air Daun Gandarusa (Justicia gendarussa Burm. F.) pada Mencit Swiss Webster. Jurnal Matematika dan Sains. 2002;7(2):57-62.

6. Kurniawan A. Uji Aktivitas Antioksidan Menggunakan Radikal 1,1-Difenil-2Pikrilhidrazil (DPPH) dan Penetapan Kandungan Fenolik Total Fraksi Etil Asetat Ekstrak Etanolik Herba Seledri (Apium graveolens L.) (Skripsi). Yogyakarta : Universitas Sanata Darma, 2011.

7. BPOM RI. Peraturan Kepala BPOM RI No. 7 Th. 2014, Tentang Pedoman Uji Toksisitas Non Klinik secara In Vivo. No. 875, 2014

8. Zuraida. Analisis Toksisitas Beberapa Tumbuhan Hutan Dengan Metode Brine Shrimp Lethality Test (BSLT). Jurnal Penelitian Hasil Hutan. 2018;36(3):239246. 